\title{
A POLÍTICA INSTITUCIONAL DA UNIVERSIDADE DA AMAZÔNIA E SEUS REFLEXOS NA FORMAÇÃO DO PROFESSOR PESQUISADOR NA ÁREA DE CIÊNCIAS SOCIAIS
}

\author{
THE INSTITUTIONAL POLICY OF THE UNIVERSITY OF AMAZONIA AND ITS IMPACT ON \\ THE FORMATION OF A RESEARCH PROFESSOR IN SOCIAL SCIENCES \\ LA POLÍTICA INSTITUCIONAL DE LA UNIVERSIDAD DE LA AMAZONÍA Y SU IMPACTO \\ EN LA FORMACIÓN DE UN PROFESOR DE INVESTIGACIÓN EN CIENCIAS SOCIALES
}

\author{
Luiz Miguel Galvão Queiroz ${ }^{1}$ \\ Paulo Sérgio de Almeida Corrêa ${ }^{2}$
}

\begin{abstract}
RESUMO
Este artigo tem por finalidade analisar a política institucional da Universidade da Amazônia - UNAMA e seus reflexos na formação do professor pesquisador da área de Ciências Sociais, mediante a descrição da atividade de pesquisa na prática docente no Curso de Ciências Sociais na referida instituição de ensino, representada pelo quantitativo da produção científica.
\end{abstract}

PAlAVRAS-CHAVE: Universidade da Amazônia. Professor pesquisador - Formação. Política institucional.

\section{ABSTRACT}

This article aims to analyze the institutional policy at the University of Amazônia - UNAMA and its effects on the formation of a research professor in the area of Social Sciences, by the description of the research activity in the teaching practice in the Course of Social Sciences in that educational institution, represented by the quantitative of scientific production.

KEYWORDS: University of Amazonia. Researcher teacher - Training. Institutional policy.

\section{RESUMEN}

Este artículo tiene como objetivo analizar la política institucional de la Universidad de la Amazonia - UNAMA y sus efectos sobre la formación de un profesor de investigación en el área de Ciencias Sociales, por la descripción de la actividad de investigación en la práctica docente en el Curso de Ciencias Sociales en esa institución educativa, representado por el cuantitativo de la producción científica .

PAlABRAS ClAVE: Universidad de la Amazonia. Profesor de investigácion - Formación. Política institucional.

\footnotetext{
1 Técnico em Educação da Secretaria de Estado de Educação do Pará. Pesquisador do Núcleo de Estudos e Pesquisa em Educação e Currículo-NEPEC-UFPA. E-mail: mscluiz59@ hotmail.com

${ }^{2}$ Professor Associado Nível 3 na Cadeira de História da Educação da Faculdade de Educação do Instituto de Ciências da Educação da Universidade Federal do Pará. E-mail: paulosac@ufpa.br
}

Recebido em: 29/06/2015 - Aceito em: 13/08/2015 


\section{INTRODUÇÃO}

Este artigo tem por finalidade analisar a política institucional da Universidade da Amazônia - UNAMA e seus reflexos na formação do professor pesquisador da área de Ciências Sociais, mediante a descrição da atividade de pesquisa na prática docente no Curso de Ciências Sociais na referida instituição de ensino, representada pelo quantitativo da produção científica.

A transposição do status de faculdade isolada para universidade provocou mudanças na organização administrativa e pedagógica na UNAMA ocasionando alterações no trabalho dos professores, vinculando a atividade de pesquisa como um apêndice destinado à produção do conhecimento.

Tal estratégia teve como finalidade cumprir com as exigências previstas na Lei de Diretrizes e Bases da Educação Nacional no 9394/96, no artigo 53 Inciso III, que trata do estabelecimento de planos, programas e projetos de pesquisa científica a serem desempenhados nas instituições de ensino superior, tal qual a UNAMA.

Esse cenário se construiu em meio à expansão do ensino superior no âmbito privado na cidade de Belém, no Estado do Pará, reconfigurando as perspectivas para as atividades dos docentes do Curso de Ciências Sociais da UNAMA. Frente ao quadro estabelecido, problematizou-se a seguinte questão: Sob quais estratégias foram instituídas as políticas de estímulo à produção do conhecimento científico nessa instituição de ensino superior?

O percurso metodológico realizado constou da seleção de documentos que circulam na UNAMA, destacando o Regimento, Estatuto, Plano de Desenvolvimento Institucional, Projeto Pedagógico do Curso de Ciências Sociais, Relatório da FIDESA, Currículo Lattes, Resoluções e Pareceres.

Priorizou-se na análise a conectividade apresentada entre os documentos que circulam no cotidiano institucional buscando extrair a subjetividade posta nas determinações normativas destinadas à operacionalidade das atividades, fundamentando-se teoricamente em Le Goof (2002) que apreende o documento carregado de ideologias e manifestações do pensar e do sentir de quem o produz, portanto, cabe ao pesquisador desconfiar e inquirir o teor da informação abrigada no suporte da documentação examinada.

\section{A POLÍTICA DE EXPANSÃO DO ENSINO SUPERIOR NA UNAMA}

O processo de ocupação e integração da região amazônica teve nas estratégias do governo pós-64, o desenvolvimento de projetos econômicos e industriais, o que favoreceu a implantação de instituições privadas de ensino superior, cuja finalidade atendia aos interesses dos empresários da educação, os quais vislumbravam novas perspectivas de acumulação por meio da prestação de serviços educacionais em função da restrição, porque passava a política estatal neste nível de ensino. 
A explosão de crescimento destas instituições aconteceu segundo critérios econômicos. Como prova disto tem-se as instituições que surgiram para suprir uma expectativa ou necessidade da sociedade local ou regional. Surgem pelo interesse de atuar em áreas geográficas economicamente atrativas para o empreendimento em questão (COLOSSI, et al, 2001, p.52).

Segundo Pinto (2002), o desenvolvimento amazônico implicou na formação de capital humano para ocupar os postos de comando nas atividades produtivas surgidas em decorrência das obras de infraestrutura nos grandes projetos instalados na região, já que a importação de técnicos de outras regiões do país, em especial do Sudeste, era insuficiente em decorrência da falta de adaptação desses sujeitos às peculiaridades regionais.

De acordo com Cunha (2005), a presença de grupos empresariais na educação superior elevou a oferta de vagas e de cursos destinados à formação de profissionais para atender expectativas envelopadas em fabuloso discurso de suposto acesso ao mundo do trabalho.

No início da década de 1970, na cidade de Belém, a oferta de cursos superiores deu-se a partir das iniciativas dos grupos empresariais da educação, concentrado nas áreas de Ciências Exatas e Humanas, destacando os cursos de Direito, Economia, Administração, Ciências Contábeis e Engenharia Civil, e Arquitetura (RELATÓRIO FICOM, 1975).

A restrição de vagas nas instituições de ensino superior público com elevado índice de excedentes ocasionou um aumento das demandas nos cursos mantidos pelas instituições privadas, em especial, do aluno-trabalhador, a partir do funcionamento de cursos noturnos.

Assim, no início da década de 1980, as instituições privadas de ensino instalaram um novo ciclo no Estado do Pará, por meio de faculdades isoladas, contando com uma infraestrutura de funcionamento destinada ao ensino, com o objetivo de formar profissionais em nível superior para atender às demandas mercadológicas.

Em nível comparativo nos aspectos quantitativos, percebe-se que houve demanda significativa em relação ao acesso aos cursos superiores oferecidos pela UNAMA, desde o momento em que o grupo mantenedor operava de forma isolada, revelando que na insuficiência do Estado na oferta do ensino superior público, as entidades privadas catalisam as demandas sociais, conforme pode ser observado na tabela a seguir.

TABELA 1 - Proporção das vagas ofertadas e preenchidas no ensino de graduação da UNAMA, segundo os Cursos - 1974-2008)

\begin{tabular}{l|l|c|c|c}
\hline ANO & CURSO & Vagas Ofertadas & Vagas Preenchidas & Demanda \\
\hline 1974 & Economia & 40 & 40 & 1,5 \\
\hline & Administração & 40 & 40 & 1,8 \\
\hline & Ciências Contábeis & 40 & 40 & 1,3 \\
\hline & Engenharia Civil & 40 & 40 & 1,2 \\
\hline 2008 & \multicolumn{5}{l}{} \\
\hline & Economia & 50 & 45 & 1,8 \\
\hline
\end{tabular}




\begin{tabular}{l|l|l|l|l}
\hline & Administração & 50 & 42 & 1,3 \\
\hline & Ciências Sociais & 50 & 48 & 1,1 \\
\hline & Ciências Contábeis & 50 & 48 & 2,1 \\
\hline & Engenharia Civil & 50 & 43 & 1,4 \\
\hline
\end{tabular}

Fonte: Secretaria Acadêmica UNAMA, 2009.

A docência nos cursos superiores era exercida por professores vinculados à universidade pública, em especial aqueles que não detinham o regime de dedicação exclusiva e também de renomados profissionais liberais, que atuavam na esfera pública e privada.

A experiência profissional era um dos requisitos básicos exigido pelas instituições privadas de ensino superior para o exercício da docência, visando formar profissionais em nível superior com competência técnica o suficiente para responder às expectativas do mundo do trabalho. A qualidade do ensino estava ligada ao saber-fazer do profissional que se dedicava à docência, pois a finalidade primária da educação superior visava à formação do capital humano (FRIGOTTO, 2003).

A política de desenvolvimento traçada pelo Governo Federal para a região amazônica teve reflexos na educação superior privada, e no final da década de 1980, houve a fusão da Faculdade Colégio Moderno com o Centro de Estudos Superiores, resultando na formação da União das Escolas Superiores do Pará - UNESPA, mantendo e ampliando a oferta de cursos superiores, destacando os cursos de Arquitetura, Pedagogia, Serviço Social, Ciências Sociais, e licenciatura em Matemática, Letras, e outros cursos (CONSELHO FEDERAL DE EDUCAÇÃO, Parecer nº 641/90).

Tal fusão teve impactos midiáticos significativos na sociedade paraense através da informação circulada nos jornais locais, com destaque a ousadia dos mantenedores em lutar para o estabelecimento de mais uma universidade no Estado do Pará.

\footnotetext{
Nasce mais uma universidade no Estado do Pará. A fusão das Faculdades Integradas Colégio Moderno - FICOM e o Centro de Educação Superior do Pará CESEP, foi regozijada na tribuna da Assembleia Legislativa pelo Deputado Nicias Ribeiro, que discursou sobre a importância da recém-criada Universidade da Amazônia para contribuir com o desenvolvimento econômico e social do Estado do Pará, através da formação de profissionais em nível superior, parabenizando os professores Edson Franco, Clodomir Colino, Antonio Vaz, pela conquista (JORNAL O LIBERAL, $2^{\circ}$ Caderno, p.2, 23.06.1993).
}

A justificativa técnica para autorização e funcionamento da UNAMA é ressaltada na experiência da Sociedade Civil Colégio Moderno - FICOM, e da Associação Paraense de Ensino e Cultura - CESEP, na educação superior privada no Estado do Pará, inclusive com a obtenção de autorização e reconhecimento para o funcionamento de cursos superiores.

Resumidamente, a Relatora extrai o que a Instituição apresenta como marcas de sua existência atual e que deram base para o pleito que formula:

- a Instituição mantém a realização de vestibulares simultâneos, em mesmo dia e hora, das instituições oficiais; 
- mantém um profundo liame com os seus egressos, através de uma Associação de Antigos Alunos, existente no seu próprio ambiente;

- promove sistemática avaliação institucional;

- mantém um Fundo de Bolsas Reembolsáveis de Graduação, com escolha dos beneficiários pelos próprios alunos;

- possui um sistema de ensino à distância, destinado ao ensino médio e ao treinamento profissional, aprovado pelo Conselho de Educação do Estado do Pará;

- destina percentuais próprios da receita de anuidades para expansão do acervo bibliográfico, para capacitação docente e para treinamento de seus recursos humanos (BRASIL, Parecer 641/90. Conselho Federal de Educação, 1990)

A União das Escolas Superiores do Pará - UNESPA permitiu expandir a oferta de cursos superiores no Estado do Pará, com a criação de dois campi localizados na área central da cidade de Belém, sito à Avenida Quintino Bocaiúva e na Avenida Alcindo Cacela.

A organização dos cursos de diversas áreas do conhecimento pela UNESPA foi o passo inicial para a consolidação do projeto de criação da UNAMA, na década de 1990, no momento em que a educação superior privada já alcançava significativo espaço no Estado do Pará, atendendo às demandas para a formação de profissionais em nível de graduação.

As mudanças apresentadas no cenário amazônico intensificaram as perspectivas destinadas ao ensino, pesquisa e extensão, componentes que caracterizam a universidade, e a partir de tal lógica, a idealização do projeto de expansão da educação superior privada, proposto para a criação da UNAMA proclamava:

\footnotetext{
A Universidade da Amazônia pretende através de suas funções de: Ensino - ser uma agência formadora de recursos humanos demandados pela sociedade amazônica, ainda muito pobre neste campo; Pesquisa - ser uma instituição voltada para a sua própria qualificação tornando-se em centro promotor e incentivador da descoberta de novos conhecimentos, com vistas ao desenvolvimento científico e tecnológico da Região Amazônica; Extensão - ser uma instituição comprometida com o desenvolvimento regional, a partir da expansão do conhecimento produzido que deverá ir até os mais distantes rincões da Amazônia (CONSELHO FEDERAL DE EDUCAÇÃO, Parecer nº 641/90).
}

A consolidação do projeto de constituição dessa instituição incluía o tripé ensino, pesquisa e extensão como estratégia destinada à elevação da qualidade da formação acadêmica, contribuindo para ampliar o conhecimento sobre a região.

Em relação ao ensino, o projeto visava formar e preparar profissionais graduados e pós-graduados nas diversas carreiras existentes e demandadas pela sociedade, dotados de qualidade formal e política, com sólida formação ética, científica, espiritual e tecnológica.

Quanto à atividade de pesquisa, esta se apresentava no plano simbólico como funçãochave da Universidade, nos domínios da ciência e da técnica, como instrumento e meio para aperfeiçoar a qualidade do ensino e como fator integrador, gerador de novos conhecimentos.

$\mathrm{Na}$ atividade de extensão, esta vertente se constituía instrumento de integração da universidade com a comunidade, por meio do ensino, pesquisa e serviços, através de 
múltiplos meios e instrumentos, trazendo a comunidade para dentro da instituição e levando a ela os resultados da prática pedagógica, técnica e científica (CONSELHO FEDERAL DE EDUCAÇÃ̃, Parecer nº 641/90).

A vocação da UNAMA em seus objetivos contempla em sua função regional as seguintes preocupações: preservar, promover e desenvolver a cultura regional, fortalecendo a identidade amazônica da população, seus valores éticos, artísticos e tecnológicos, além de promover a integração, o intercâmbio e a cooperação com as demais instituições de ensino no Estado do Pará.

Ao fazer parte do Protocolo das Instituições Superiores do Pará ${ }^{3}$, a UNAMA assumiu o compromisso de participar nas ações destinadas à promoção da integração entre as instituições de ensino público e privado, e tal cooperação implicou em maior dinamicidade no diálogo para fortalecer os estudos e pesquisas desenvolvidas em parceria.

A caracterização institucional a partir da plena integração do ensino com a pesquisa e a extensão, é anunciada como ponto de partida e chegada. A pesquisa promoverá a investigação dos meios de melhoria da qualidade do ensino e voltada para os avanços científicos, impulsionadores de novos caminhos do saber. A extensão integrará o ensino com as necessidades da comunidade regional e nacional, abrindo-se, igualmente, aos grandes temas da atualidade internacional (CONSELHO FEDERAL DE EDUCAÇÃO, Parecer $n^{\circ}$ 641/90).

Para atingir os objetivos propostos no projeto dessa nova Universidade, o quadro docente contratado inicialmente era formado por 461 professores, sendo 142 titulares; 74 Adjuntos; 76 Assistentes e 169 Auxiliares (CONSELHO FEDERAL DE EDUCAÇÃO, Parecer $n^{\circ}$ 641/90).

A qualificação acadêmica dos professores foi um dos principais entraves no processo de criação da Universidade da Amazônia, pois a dificuldade de encontrar docentes com titulação em mestrado e doutorado na região amazônica no final de década de 1980 e início da década de 1990 era evidenciada, conforme registrado nas fontes documentais oficiais que circulavam no referido período.

\footnotetext{
A situação docente quanto à titulação revela que a Instituição, apesar dos esforços já realizados, mandando seus professores para cursos de mestrado e doutorado e contemplando-os, além das bolsas da CAPES e CNPq, ainda tem um percentual muito restrito de docentes com mestrado, como aliás ocorre na Região Amazônica (CONSELHO FEDERAL DE EDUCAÇÃO, Parecer nº 641/90).
}

Os professores eram admitidos mediante contrato com a entidade mantenedora, segundo as normas existentes e por indicação dos Departamentos à Diretoria de Ensino. O sistema de promoção de uma categoria a outra obedecia a Resolução específica referente à

\footnotetext{
${ }^{3}$ Protocolo criado em 2001, com a participação da Universidade Federal do Pará, Universidade Federal Rural da Amazônia, Universidade do Estado do Pará, Universidade da Amazônia, Centro Tecnológico do Pará e Instituto Federal de Educação, Ciência e Tecnologia.
} 
carreira docente, aprovada em acordo com os professores. Dentre os critérios levados em consideração ao exercício da docência, destacavam-se a qualificação formal, a experiência profissional, a vivência no campo da pesquisa e da extensão (RESOLUÇÃO UNESPA, ${ }^{\circ}$ 12, 1987).

Esta Resolução também definia o regime de trabalho dos docentes na Instituição, conforme as seguintes categorias: Professor-horista; Professor de Regime de Tempo Contínuo, com 20 ou 40 horas; Professor de Regime de Tempo Contínuo Integral.

A UNAMA implantou, ainda na década de 1990, uma política de expansão do ensino superior no Estado do Pará, priorizando cursos nas áreas das Ciências Humanas, destacando os cursos de Psicologia, Fonoaudiologia, Jornalismo, Secretariado Executivo Bilíngue.

No processo seletivo de 1995, a demanda nos referidos cursos foi representativa destacando os cursos de Psicologia, Fonoaudiologia e Jornalismo. Já no curso de Secretário Executivo Bilíngue, houve queda na demanda, resultando no posterior fechamento do curso.

GRÁFICO 1 - Oferta, Demanda e Vagas Preenchidas nos Cursos

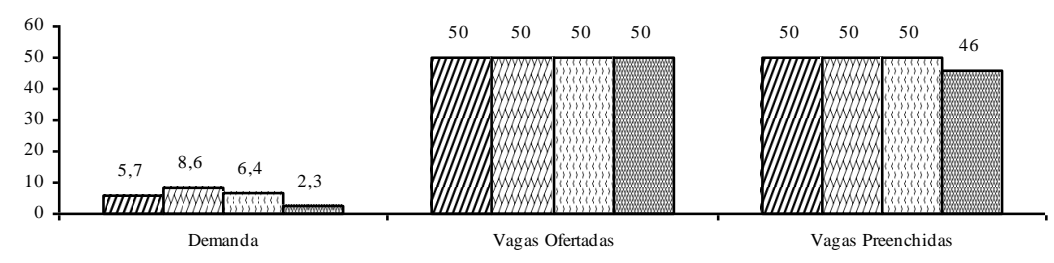

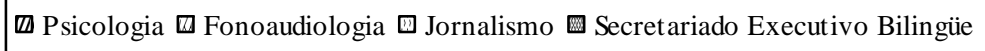

Fonte: Secretaria Acadêmica UNAMA

Apoiada nas perspectivas de desenvolvimento social e econômico que se configuravam na região amazônica no final da década de 1980, o projeto de expansão da UNAMA veio a concretizar-se em 1993. A implantação da primeira Universidade privada no Estado do Pará refletiu significativamente na ampliação das vagas no ensino superior.

Centralizado na formação do capital humano para satisfazer demandas do mercado, o projeto de expansão do ensino superior capitaneado pela instituição UNAMA, cumpria as expectativas dos segmentos sociais, em especial do aluno-trabalhador, que diante do restrito acesso ao ensino superior público, doravante tinha a opção do ensino privado como meio de alcançar a formação em nível de graduação.

Visando atender às metas que se desenharam no Plano de Desenvolvimento Institucional - PDI de 1995 para a qualificação dos docentes, foram firmados convênios interinstitucionais, cujo objetivo consistia em elevar a titulação dos professores, em nível de mestrado e doutorado.

A partir do final da década de 1990, ocorreu o processo de interiorização, com a oferta de cursos de licenciatura em regime de convênio com prefeituras municipais, destinado à 
formação de professores. Os cursos oferecidos constam da licenciatura em Letras, habilitação em Língua Portuguesa, Matemática, e Pedagogia - habilitação nas séries iniciais do ensino fundamental, com oferta de 50 (cinquenta) vagas, ressaltando um percentual de 2,8 candidatos/vagas no curso de Letras, 2,2 no curso de Matemática, e 1,8 no de Pedagogia (SUPERINTENDENCIA DE INTERIORIZAÇÃO, UNAMA, 2000).

As reformas educacionais protagonizadas a partir da promulgação da Lei de Diretrizes e Bases no 9394/96 refletiram na educação superior, em especial, na exigência de titulação para o exercício da docência, resultando em mudanças no perfil e na qualificação dos professores da Universidade da Amazônia, conforme revela o enunciado discursivo descrito abaixo.

\begin{abstract}
A titulação mínima exigida é a de Mestre ou Doutor. São admitidos Especialistas nos cursos em que os professores são mais profissionais da área e, portanto, não possuem Mestrado ou Doutorado [...] O corpo docente é selecionado com base na titulação e na experiência no magistério superior e na área profissional em que atua, mantendo a congruência com a disciplina a ser lecionada. Para a admissão exige-se um mínimo de tempo de experiência docente e profissional, conforme estabelecido na carreira do magistério da UNAMA (PLANO DE DESENVOLVIMENTO INSTITUCIONAL, 2008).
\end{abstract}

A qualificação dos professores fez parte do processo de expansão do ensino superior realizado nessa instituição, visando atender às diretrizes constantes no Planejamento Estratégico da instituição, buscando-se garantir a qualidade do ensino ofertado à sociedade, assim como estabelecer condições objetivas para disputar recursos financeiros junto às agências de fomento.

Atualmente seu quadro docente é formado por professores com nível de titulação exigida pela Legislação Educacional vigente, de modo que a política de expansão fez com que o perfil desses sujeitos se alterasse em face das determinações legais.

GRÁFICO 2 - Evolução da Titulação dos Docentes da UNAMA

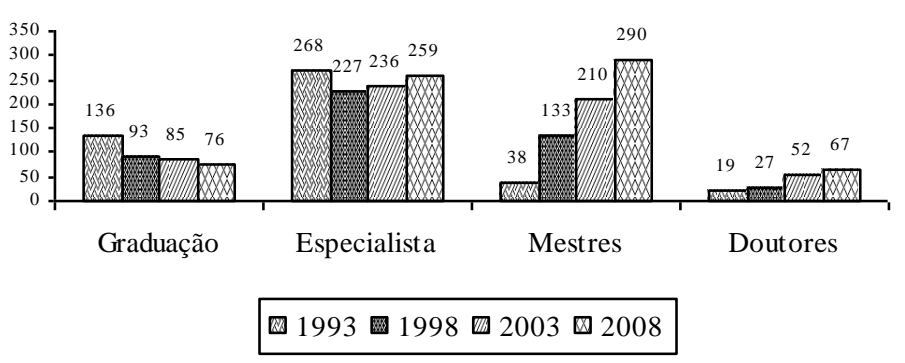

Fonte: Plano de Desenvolvimento Institucional - UNAMA, 2008.

A expansão do ensino superior nesse espaço acadêmico teve como consequência a elevação do nível de qualificação dos professores, destacando a presença de um maior contingente de especialistas e mestres nos períodos analisados. 
A diminuta participação de doutores na composição do quadro evidencia a dificuldade para pleitear fomento, uma vez que as agências têm priorizado esse segmento como parâmetro de incentivo e distribuição orçamentária.

As pressões das entidades representativas de pós-graduação e a promulgação da Lei de Diretrizes e Bases 9394/96, exigindo no artigo 52 um contingente de 1/3 de professores com qualificação em nível de mestrado ou de doutorado na composição do quadro de docentes nas universidades repercutiu na mudança desse panorama.

Percebe-se no ciclo evolutivo da qualificação dos docentes da UNAMA a queda do quantitativo de professores com graduação, no entanto, aqueles profissionais com titulação de especialização se mantiveram equilibrados.

Essas modificações sugerem que a qualificação dos docentes em nível de mestrado e doutorado contribuiu para o fortalecimento da pesquisa no âmbito institucional, e de acordo com as perspectivas destinadas para a realização desta atividade, o aprofundamento do conhecimento da realidade social da Amazônia poderia ser desenvolvido mediante o trabalho investigativo dos poucos professores qualificados para essa tarefa.

Logo, a trilogia ensino-pesquisa-extensão tão anunciada no discurso institucional, não chega a se cumprir junto a grande parte do corpo docente existente.

A qualificação dos professores reflete o contexto da região amazônica em geral, em que a carência de mestres e doutores é significativa, resultando na tomada de medidas por parte das instituições de ensino privado do incentivo por meio de bolsas e convênios interinstitucionais para promover a formação continuada de seu quadro docente.

\section{A ATIVIDADE DE PESQUISA NA PRÁTICA DOCENTE NO CURSO DE CIÊNCIAS SOCIAIS DA UNAMA}

A atividade de pesquisa consta dentre os objetivos fundamentais da UNAMA, destacando seu papel em contribuir com o avanço do conhecimento sobre a região, o que implica na presença de pesquisadores como parte integrante de seu quadro funcional, inseridos em projetos e programas, articulados ao ensino e à extensão.

\footnotetext{
Art. 4 - A UNAMA tem por objetivos: I - estimular a criação cultural e o desenvolvimento do espírito científico e do pensamento reflexivo; [...] III promover a pesquisa e a investigação científica, visando o desenvolvimento da ciência e da tecnologia e a criação e difusão da cultura, desenvolvendo o entendimento do homem e do meio amazônico em que vive (ESTATUTO UNAMA, 1993).
}

A pesquisa é anunciada como parte constituinte da cultura institucional, sendo, portanto, capaz de reverter à sociedade o conhecimento produzido por cientistas através de programas e projetos desenvolvidos, dos quais fazem parte professores e alunos, estes beneficiados com a política de Bolsas de Iniciação Científica. Ao ser criada a 
Superintendência de Pesquisa em 1993, houve um movimento em favor do estímulo à Iniciação Científica por meio de projetos com a participação de alunos.

No Regimento Geral da UNAMA, a atividade de pesquisa está subordinada à PróReitoria de Pesquisa, Pós-Graduação e Extensão, e dentre suas finalidades consta o planejamento, coordenação, supervisão e avaliação dos programas de pesquisa.

Nesta atividade, o envolvimento dos professores é de fundamental importância, seja na coordenação, como também na prática investigativa, resultando na produção de conhecimento científico. Por outro lado, a instituição inclui a prestação de consultoria a entidades públicas e privadas, mediante convênios e contratos, conforme previsto no Estatuto da Universidade e no Regimento Geral.

Para desenvolver a atividade de pesquisa no âmbito institucional, a UNAMA, prevê a aplicação de $1 \%$ da receita obtida com a cobrança das anuidades para os programas de pesquisa que efetiva, e busca financiamento por meio de parceiras com instituições públicas e privadas (REGIMENTO INTERNO, UNAMA).

A fim de sistematizar as atividades de pesquisa, foram criados espaços institucionais, tais como: Núcleo de Estudos e Pesquisas em Educação; Núcleo de Estudos e Pesquisas Sócio-Econômicas; Núcleo de Estudos e Pesquisas de Qualidade de Vida e Meio Ambiente; Núcleo de Estudos e Pesquisas em Ciência Jurídica (UNAMA, Resolução CONSUN nº 005/98).

Estes espaços acadêmico-científicos, portanto, têm por finalidade estimular a produção do conhecimento, além de manter intercâmbio com instituições da região, do país e do exterior, que desenvolvem estudos e pesquisas nas áreas de conhecimento em que atuam (PLANO DE DESENVOLVIMENTO INSTITUCIONAL, 2008).

A atividade de pesquisa desempenha uma função estratégica visando o fortalecimento do intercâmbio e a discussão de aportes teóricos e metodológicos entre os cientistas que atuam na Amazônia, e a cooperação de centros de excelência nacionais e internacionais.

A pesquisa passou a ser a base que fundamenta o processo de formação do professor para atuação na educação superior, requisito expresso no Plano de Desenvolvimento Institucional da carreira do magistério na UNAMA, além de representar um dos requisitos para credenciamento dos cursos autorizados a funcionar.

De acordo com o referido documento, a própria instituição estimula o seu corpo docente ao ingresso em planos de qualificação, seja através de ajuda de custo (para cursos fora do Estado ou do País), ou mediante concessão de licença remunerada ou não, intercâmbio com outras instituições, palestras, congressos, seminários e outros. Estimula e apoia, ainda, a publicação de artigos científicos, capítulos de livros e livros, assim como dissertações de mestrado e teses de doutorado. 
A formação continuada dos docentes na UNAMA se vale das prerrogativas constantes na aliança público-privado, fazendo uso dos benefícios vinculados aos protocolos e programas destinados à qualificação dos professores nos níveis de mestrado, doutorado, pósdoutorado, e participação em projetos de pesquisa com financiamentos externos.

Tal prática reduz os investimentos próprios da instituição em atividades de pesquisa, exigindo-se em algumas situações aos professores, que submetam projetos de pesquisa para captação de recursos voltados ao desenvolvimento de estudos, visando justificar e manter o status de universidade.

A academia pode ser um espaço onde os professores e os pesquisadores tenham oportunidades de interlocução, gerando e compartilhando conhecimentos, tomando contato com realidades diferentes e ampliando a compreensão do processo educativo e formativo [...] esse pode ser um instrumento poderoso de fortalecimento da profissão docente (PEREIRA e ALLAIN, 2006, p.272).

De acordo com a matriz curricular atual do Curso de Ciências Sociais dessa instituição, a pesquisa relaciona-se diretamente ao processo de formação do profissional, a partir do estudo, da investigação a respeito de problemas relacionados com a vida real, da sociedade, do mundo, trabalho, da profissão, favorecendo a leitura e interpretação da realidade a partir dos conteúdos disciplinares.

No entanto, é relevante destacar a atividade de pesquisa como estratégia capaz de justificar o status de universidade concedido pelo Ministério da Educação, e para tanto, se requer o cumprimento dos trâmites legais, nos quais a qualificação pós-graduada do professor é um dos requisitos para sustentação de tal prestígio acadêmico.

Na análise da LDB, fica manifesto que o docente universitário deve ter
competência técnica, compreendida como domínio da área de conhecimento. Tal
competência aparece em seu artigo 52 (definidor de Universidade), incisos II e III,
onde é determinado que as universidades são instituições que se caracterizam por:
II . um terço do corpo docente, pelo menos com titulação acadêmica de mestrado
ou doutorado; III . um terço do corpo docente em regime de tempo integral
(MOROSINI, 2000, p. 12).

Por volta do ano de 2003, portanto, dez anos após ter sido criada, a UNAMA já apresentava um contingente de 262 professores com titulação em mestrado e doutorado, padrão esse alcançado em decorrência dos incentivos para a qualificação constante no Plano de Desenvolvimento Institucional, que sinalizava para a expansão de suas atividades de ensino com a abertura de mais campi, dotado de arquitetura opulenta, localizado na área metropolitana da cidade de Belém, com realce na expansão da urbe em direção à saída da cidade, além de firmar parcerias com instituições de ensino que mantém programas de mestrado e doutorado. 


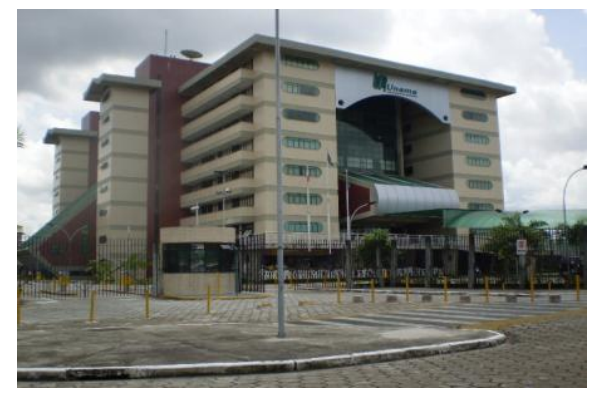

FOTO 1 - Campus BR-316

A reflexão sobre a atividade de pesquisa desenvolvida pelos docentes do Curso de Ciências Sociais da UNAMA vem ao encontro das determinações legais, para que se garanta o funcionamento institucional nesta categoria de ensino superior. Assim, é possível perceber, a partir da análise da matriz curricular do curso, que as atividades interdisciplinares realizadas com os alunos por meio de projetos e outras ações, caracterizam-se como tal.

A produção científica institucionalizada é um dos requisitos essenciais da universidade. Em sentido estrito, ela se faz no âmbito do ensino, em função da pesquisa realizada e do desenvolvimento da extensão. Em sentido compulsório, através dos programas de pós-graduação (PLANO DE DESENVOLVIMENTO INSTITUCIONAL DA UNAMA, 2008).

A política de produção científica instituída ressalta o valor da pesquisa como um dos eixos justificadores de sua condição. Assim, ela se manifesta na prática docente como parte constituinte do processo de formação e qualificação dos discentes, e obrigatoriamente nos programas de pós-graduação mantidos pela instituição.

Para desenvolver a atividade de pesquisa, a instituição conta com diversas fontes de captação, dentre elas, convênios com prefeituras, empresas, instituições governamentais, as quais se revertem para aprofundar o conhecimento científico sobre a região amazônica, ao mesmo tempo em que colocam os professores em contato com problemas complexos, os quais podem ser desvendados por meio da atividade investigativa.

A UNAMA atua como agência de captação de recursos financeiros junto às instâncias governamentais, por meio da FIDESA, para desenvolver estudos e pesquisas na região amazônica, além de buscar investimentos para qualificar seus professores em programas de mestrado, doutorado, pós-doutorado, e esta prática tem sido utilizada estrategicamente por seu grupo mantenedor.

\section{A PRODUÇÃo CIENTÍfICA DOS PROFESSORES DO CURSO DE CIÊNCIAS SOCIAIS DA UNAMA}

O desenho curricular do Curso de Ciências Sociais da UNAMA contempla um conjunto de 33 disciplinas ministradas ao longo de quatro anos, com caracterizações teóricas e práticas para a formação profissional do Sociólogo. A necessidade de investigar a realidade social amazônica em sua complexidade evidenciou-se na reforma curricular do curso realizada no início da década de 2000, ressaltando os aspectos relacionados à diversidade

\begin{tabular}{l|l|l|l|l|l|l} 
(C) Rev. Inter. Educ. Sup.[RIESup] & Campinas, SP & v.1 & n.1 & p. 32-49 & jul./set. 2015 & ISSN 2446-9424 \\
\hline
\end{tabular}


humana, social e política como objeto de investigação científica, visando oferecer ao graduando um quadro panorâmico da realidade em que supostamente atuará.

Assim, o Curso de Ciências Sociais admite uma proposta interdisciplinar na formação do Sociólogo possibilitando a reflexão sobre a cultura, os processos socioeconômicos que interferem na vida do homem do campo, o processo de urbanização, as relações de poder local, as relações de gênero, religiosidade, meio ambiente, e outras temáticas de relevância social, investigadas e abordadas a partir de um referencial teórico-metodológico favorável ao desenvolvimento da pesquisa científica (PROJETO PEDAGÓGICO, 2008).

Num contexto mais amplo, o curso visa oferecer aos seus acadêmicos uma tripla formação, envolvendo os seguintes eixos: a) formação para o ensino, visando desenvolver competências didático-pedagógicas com base em habilidades de exposição, argumentação e análise teórica; b) a formação para a pesquisa visa fornecer fundamentação e treinamento teórico-metodológico para atuar em atividades de pesquisa, seja na carreira acadêmica ou fora dela, como agentes produtores, divulgadores e debatedores de novos conhecimentos no âmbito das ciências sociais e de áreas afins; c) a formação para o mercado de trabalho tem como objetivo desenvolver competências reflexivas, analíticas e técnico-instrumentais, valorizadas em diferentes áreas sociais, (organizações governamentais e não governamentais, partidos políticos, movimentos sociais, sindicais e similares).

A complexidade da região amazônica tornou-se objeto de investigação no Curso de Ciências Sociais em várias atividades propostas no projeto pedagógico, sistematizando-se o conhecimento em seminários interdisciplinares, semanas acadêmicas, publicação sistemática de artigos em periódicos locais, livros, projetos de pesquisa, palestras, mesas redondas, etc.

TABELA 2 - Quadro sinóptico de periodização dos eventos

\begin{tabular}{|c|c|}
\hline Atividade & Periodicidade \\
\hline Semana Acadêmica & $1 \mathrm{vez}$ ao ano \\
\hline Seminários interdisciplinares & $1 \mathrm{vez}$ ao ano \\
\hline Palestras & 2 por semestre \\
\hline Mesa Redonda & 2 mesas por ano \\
\hline
\end{tabular}

Fonte: Calendário Acadêmico do Curso de Ciências Sociais, 2008.

De acordo com o Projeto Pedagógico desse Curso, o corpo docente é composto por um total de 20 professores, com titulação de especialista, mestrado e doutorado, buscando-se articular o preparo intelectual relacionando o ensino com a pesquisa na formação profissional. As reformas curriculares para o curso de Ciências Sociais colocaram em relevo a pesquisa como base para a formação do sociólogo, o que levou as instituições de ensino a reformular suas bases curriculares, apresentando ressonância na formação e na atividade docente, conforme o gráfico abaixo.

GRÁFICO 3 - Titulação do quadro docente do curso de Ciências Sociais da UNAMA

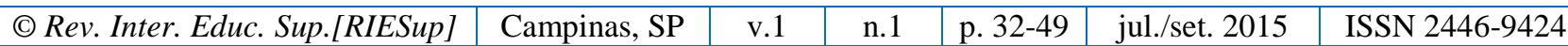




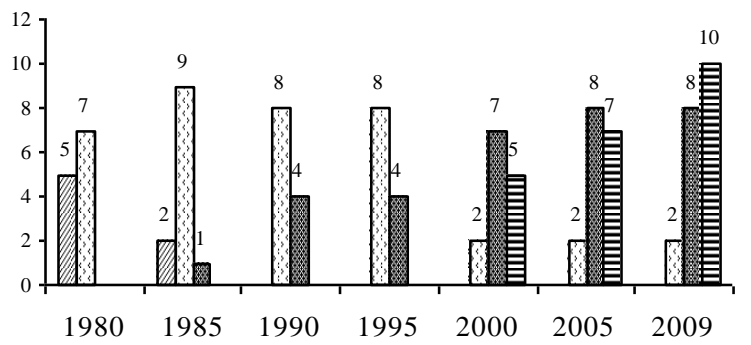

四 Graduação 0 Especialista 圆 Mestrado 目 Doutorado

Fonte: Relatório Superintendência de Ensino e Pesquisa - UNAMA

Havia um percentual significativo de professores com qualificação suficiente para o desenvolvimento das atividades de pesquisa. No início de seu funcionamento o curso contava com um número reduzido de professores com pós-graduação, e após dez anos, a presença de mestres já era significativa no quadro docente, de modo que professores com qualificação mínima de graduação não faziam mais parte do capital humano utilizado.

Ao iniciar o Curso de Ciências Sociais em 1980, 41\% do corpo docente detinha o nível de graduação e 58\% eram especialistas; em 1985 o contingente de professores com graduação baixou para $16 \%$, os professores especialistas elevaram o quantitativo com $75 \%$, e $8 \%$ de professores com mestrado; no ano de 1990, o quadro docente apresentava $66 \%$ de especialistas e $33 \%$ de mestres, período esse que as reformas curriculares se efetivam e as lutas em favor do ensino com pesquisa no currículo são evidenciadas. Porém, o salto na qualificação dos docentes deu-se no período de 2000, com $14 \%$ de especialistas, $50 \%$ de mestres e 35,7\% de doutores. O panorama de titulação eleva-se de 2005 a 2008 com destaque aos doutores.

Até o ano de 1995, os professores especialistas se destacavam na composição do quadro docente do curso de Ciências Sociais da UNAMA, no entanto, a partir do ano 2000 até 2009, percebe-se o aumento da quantidade de mestres e doutores, e a diminuição do quantitativo de especialistas.

Atualmente, a titulação dos professores em sua maioria (90\%) na pós-graduação projeta-se como fator potencialmente indutor da prática investigativa voltada à produção do conhecimento. Entretanto, cabe considerar que:

Não basta fornecer-lhe um certo domínio de técnicas de pesquisa, é preciso toda uma imersão num universo teórico e conceitual, onde se encontrem as coordenadas epistemológicas, políticas e antropológicas de toda discussão relevante e crítica da área [...] o pesquisador precisa vivenciar uma experiência problematizadora. Além dos subsídios que estará recebendo do acúmulo de suas intuições pessoais, ele poderá colher elementos de suas leituras, dos cursos, dos debates, enfim, de todas as contribuições do contexto acadêmico, profissional e cultural em que vive (SEVERINO, 2009, p. 19). 
A atividade investigativa destinada à produção do conhecimento entre os docentes, todavia, não ocorreu desde a implantação do curso em 1980, conforme mostra o gráfico a seguir:

GRÁFICO 4 - Produção científica dos docentes do curso de Ciências Sociais da UNAMA - 19801990

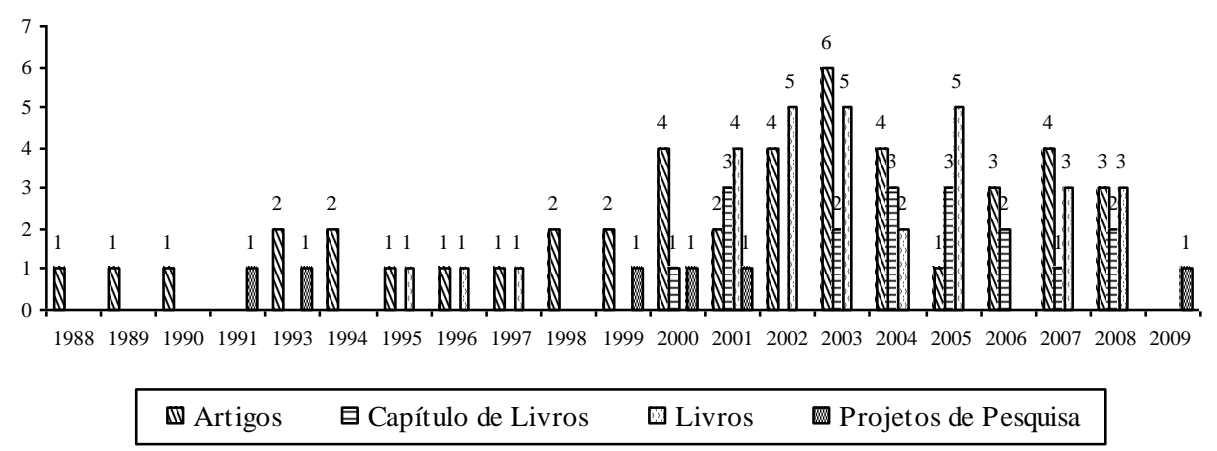

Fonte: Plataforma Currículo Lattes CNPQ

Como se pode notar, a produção científica no alvorecer do período investigado era incipiente, reduzida apenas a artigos científicos publicados. Este quadro pode ser justificado pelas limitações no financiamento das atividades de pesquisa, uma vez que a Fundação Instituto para o Desenvolvimento da Amazônia - FIDESA, instituída em 1997 pela União de Ensino Superior do Pará, com o objetivo de fomentar atividades de pesquisa, extensão e de capacitação de recursos humanos, ainda estava em consolidação, o que inviabilizava o financiamento da produção científica.

No início da década de 1990, a produção científica dos professores teve mudanças em valores quantitativos, destacando um valor expressivo de artigos publicados, livros, capítulos de livros e a implantação de projetos de pesquisa (ainda que estes tenham ocupado uma reduzida proporção). Tal quadro expressa o quanto a atividade de pesquisa se fez presente nas obrigações laborais dos docentes.

Este quadro quantitativo de produção científica foi reflexo da definição de uma política de pesquisa implantada em 1996, buscando-se fomentar o desenvolvimento de projetos e a qualificação de professores visando aprimorá-los ao exercício investigativo (UNIVERSIDADE DA AMAZÔNIA. CONSEPE. Resolução no 001/99 de 1 de fevereiro de 1999, Belém,1999).

O projeto de expansão da UNAMA contribuiu sobremaneira com o avanço na produção científica dos professores do Curso de Ciências Sociais, destacando as iniciativas para a consolidação da parceria público-privado visando à captação de recursos financeiros para o desenvolvimento de pesquisas na área social (RELATÓRIO FIDESA, 2000).

Complementando tal quadro, a elevação do nível quantitativo da produção do conhecimento resultante da atividade de pesquisa como parte constituinte da prática docente, 
esteve atrelada à política institucional mediante fomento e enquadramento funcional de parcela dos docentes em regime de tempo integral (PLANO DE DESENVOLVIMENTO INSTITUCIONAL, 2008).

Após o ano de 2000, percebe-se que houve um crescimento da produção científica dos professores, em função de novas perspectivas surgidas no âmbito do desenho curricular do curso, que passou a adotar a atividade de pesquisa como componente da ação docente.

De acordo com Severino (2009), inserir o aluno no ambiente investigativo implica no envolvimento dos professores na execução de pesquisas, não apenas no processo de orientação, pois é impossível ensinar a pesquisar sem estar pesquisando.

O Projeto Interdisciplinar é um processo de questionamento que permite favorecer a aprendizagem dos alunos a partir do estudo, da investigação a respeito de problemas relacionados com a vida real, da sociedade, do mundo, trabalho, da profissão, favorecendo a leitura e interpretação da realidade a partir dos conteúdos disciplinares. Esta é uma maneira de entender o sentido da formação, pois os alunos participam de um processo de pesquisa que tenha sentido para eles, no qual usem diferentes estratégias e meios. Favorecendo o desenvolvimento de estratégias de questionamento, de problematização, interpretação e apresentação do processo seguido, ao estudar o tema e/ou problema, falar sua complexidade, favorecer o melhor conhecimento do mundo em que vivem. A partir do estudo e pesquisa do tema ou problema, deverá culminar com a realização de um seminário, uma exposição, uma produção audiovisual, uma campanha ou outra forma de evidenciar um produto como resultado do Projeto Interdisciplinar (PROJETO PEDAGÓGICO, 2008, p. 12).

Considerando que o currículo do Curso de Ciências Sociais abrange um conjunto de fenômenos passíveis de investigação, é possível que a inserção dos professores nas atividades de pesquisa permita expandir a produção do conhecimento, sistematizada sob a forma de projetos de pesquisa, artigos científicos, livros, artigos, capítulos de livros e relatórios.

A prática docente subsidiada pela atividade investigativa resulta das novas perspectivas teóricas e epistemológicas prevalecentes na educação superior, e na Universidade da Amazônia, a pesquisa é propalada como dispositivo pedagógico diferencial nos serviços educacionais ofertados, estando evidenciado nas finalidades, nos princípios e nos objetivos da instituição contidos em seu Estatuto.

Conforme o tipo de instituição de ensino superior em que o professor atua, sua docência sofrerá diferentes pressões. Se ele atua num grupo de pesquisa em uma universidade, provavelmente sua visão de docência terá um forte condicionante de investigação. Já se ele atua numa instituição isolada, num centro universitário, ou mesmo numa federação, sua visão de docência terá um forte condicionante de ensino sem pesquisa, ou, quando muito, do ensino com a pesquisa. A cultura da instituição e daí decorrente a política que ela desenvolve terão seus reflexos na docência universitária. Entretanto, é importante ressaltar que, mesmo nas instituições universitárias, a afirmação de que todos os docentes tenham a sua atividade relacionada à pesquisa não é verdadeira. As instituições têm diferentes 
graus de desenvolvimento de pesquisa em seu interior e mesmo entre as instituições (MOROSINI, 2000, p.14).

A interferência da política científica desenvolvida pela UNAMA para elevar a qualidade do ensino dinamiza a pesquisa como parte constituinte da atividade dos docentes, e no Curso de Ciências Sociais este quadro é observado mediante a elevação da produção intelectual dos mestres e doutores que compõem o corpo docente.

\section{CONSIDERAÇÕES FINAIS}

A atividade científica dos professores do curso de Ciências Sociais nos dez primeiros anos de funcionamento era incipiente pelo fato de se revelar na proposta curricular a formação do sociólogo pautado no paradigma da racionalidade técnica, ou seja, formar quadros para atender às demandas dos postos de trabalho na esfera pública e privada, pois a presença dos Grandes Projetos incrementou e aqueceu a economia local, com a instalação de empresas e necessitava-se de pessoal para ocupação de atividades de comando e execução.

Tal situação contemplava a presença na docência no ensino superior de profissionais graduados e especialistas, como de fato ocorreu na composição do quadro docente do Curso de Ciências Sociais da UNAMA, em sua maioria composto por essa categoria de professores.

Percebeu-se que a partir da década de 1990 houve mudanças na composição do quadro de docentes com a presença de mestres e doutores ainda em percentuais diminutos, no entanto, a atividade de pesquisa já se evidenciava pertinente, inclusive com a produção intelectual representada em livros, mas com diminuta repercussão nos projetos de pesquisa.

Apesar da evolução quantitativa da qualificação do corpo docente da UNAMA apresentar níveis significativos, inclusive com impactos na produção do conhecimento conforme é apresentada entre os docentes do Curso de Ciências Sociais, percebeu-se que as mudanças ocorridas nas reformas curriculares desenharam uma nova perspectiva na proposta para a formação do sociólogo, com a sistematização de trabalhos de pesquisa e extensão, de curta duração e que se transformam em obras editadas institucionalmente.

Estes trabalhos, ao se institucionalizarem como pesquisa, circulam internamente na UNAMA e são colocados à disposição da comunidade acadêmica da instituição, tornando-se mais uma estratégia de marketing para justificar que a universidade desenvolve pesquisa.

\section{REFERÊNCIAS}

COLOSSI, Nelson. Mudanças no Contexto do Ensino Superior no Brasil: Uma tendência ao ensino colaborativo. Curitiba. Revista da Faculdade de Educação, v.4, n.1, p.49-58, jan./abr. 2001.

CUNHA, Luis C. Educação Superior no Brasil. São Paulo: Cortez, 2002. 
CUNHA, Maria Isabel. O Professor Universitário na transição de paradigmas. Araraquara: JM, 2005.

FRIGOTTO, Gaudêncio. A educação superior e as mudanças no mundo do trabalho. São Paulo: Revista Brasileira de Educação. v.1, n.4, 2003.

GUIMARÃES, Valter. Fundada a UNAMA. Jornal O Liberal. 2º caderno, p.2. 23.06.1993.

LE GOFF, Jacques. Documento/monumento. In: História e memória. 2.ed. Capinas, SP: Editora da UNICAMP, 2004.

LE GOFF, Jacques. Enciclopédia Einaudi: Lisboa, v.1, Imprensa Nacional, 2002.

MOROSINI, Marília Costa (Org.). Professor do ensino superior: identidade, docência e formação. Brasília: Instituto Nacional de Estudos e Pesquisas Educacionais, 2000.

PEREIRA, Júlio Emílio Diniz, ALLAIN, Luciana Resende. Considerações acerca do professor-pesquisador: a que pesquisa e a que professor se refere essa proposta de formação? Ponta Grossa. Revista Olhar de professor, 2006, p.269-282.

PINTO, Lúcio Flávio. A década Perdida. Belém: Grafisa, 1990.

PINTO, Lúcio Flávio. Os efeitos dos grandes projetos na Amazônia. Belém: Jornal Pessoal. v.13, n.9, 2000.

UNIVERSIDADE DA AMAZÔNIA. Informativo Acadêmico. Belém: UNAMA, 2007.

UNIVERSIDADE DA AMAZÔNIA. Estatuto UNAMA. Belém, 2008.

UNIVERSIDADE DA AMAZÔNIA. Projeto Pedagógico do Curso de Ciências Sociais da UNAMA. Belém, 2008.

UNIVERSIDADE DA AMAZÔNIA. Plano de Desenvolvimento Institucional UNAMA. Belém: UNAMA, 2008.

UNIVERSIDADE DA AMAZÔNIA. Relatório de Pesquisa. Superintendência de Pesquisa. UNAMA, Belém, 2007.

UNIVERSIDADE DA AMAZÔNIA. Relatório do Curso de Ciências Sociais. UNAMA, 2008.

UNIVERSIDADE DA AMAZÔNIA. Guia Acadêmico do Curso de Ciências Sociais. UNAMA, 2008.

UNIVERSIDADE DA AMAZÔNIA. Relatório da Superintendência de Graduação. UNAMA, 2008. 